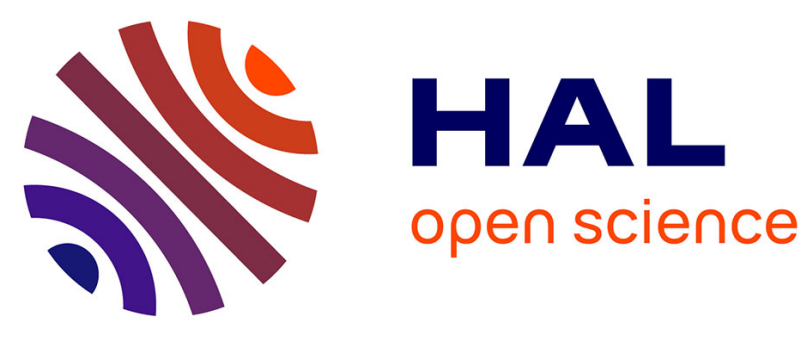

\title{
Scalable Route to Electroactive and Light Active Perylene Diimide Dye Polymer Binder for Lithium-Ion Batteries
}

Pierre Ranque, Chandramohan George, Rajeev Dubey, Remco van Der Jagt, Delphine Flahaut, Rémi Dedryvère, Marcus Fehse, Panagiotis Kassanos, Wolter Jager, Ernst Sudhölter, et al.

\section{To cite this version:}

Pierre Ranque, Chandramohan George, Rajeev Dubey, Remco van Der Jagt, Delphine Flahaut, et al.. Scalable Route to Electroactive and Light Active Perylene Diimide Dye Polymer Binder for LithiumIon Batteries. ACS Applied Energy Materials, 2020, 3 (3), pp.2271-2277. 10.1021/acsaem.9b01225 . hal-02543156

\section{HAL Id: hal-02543156 https://hal.science/hal-02543156}

Submitted on 28 Sep 2020

HAL is a multi-disciplinary open access archive for the deposit and dissemination of scientific research documents, whether they are published or not. The documents may come from teaching and research institutions in France or abroad, or from public or private research centers.
L'archive ouverte pluridisciplinaire HAL, est destinée au dépôt et à la diffusion de documents scientifiques de niveau recherche, publiés ou non, émanant des établissements d'enseignement et de recherche français ou étrangers, des laboratoires publics ou privés. 


\title{
Scalable Route to Electroactive and Light Active Perylene Diimide Dye Polymer Binder for Lithium-Ion Batteries
}

\author{
Pierre Ranque, Chandramohan George,* Rajeev K. Dubey, Remco van der Jagt, Delphine Flahaut, \\ Rémi Dedryvère, Marcus Fehse, Panagiotis Kassanos, Wolter F. Jager,* Ernst J. R. Sudhölter, \\ and Erik M. Kelder*
}

Cite This: ACS Appl. Energy Mater. 2020, 3, 2271-2277

Read Online



ABSTRACT: Developing multifunctional polymeric binders is key to the design of energy storage technologies with value-added features. We report that a multigram-scale synthesis of perylene diimide polymer (PPDI), from a single batch via polymer analogous reaction route, yields high molecular weight polymers with suitable thermal stability and minimized solubility in electrolytes, potentially leading to improved binding affinity toward electrode particles. Further, it develops strategies for designing copolymers with virtually any desired composition via a subsequent grafting, leading to purpose-built binders. PPDI dye as both binder and electroactive additive in lithium half-cells using lithium iron phosphate exhibits good electrochemical performance.
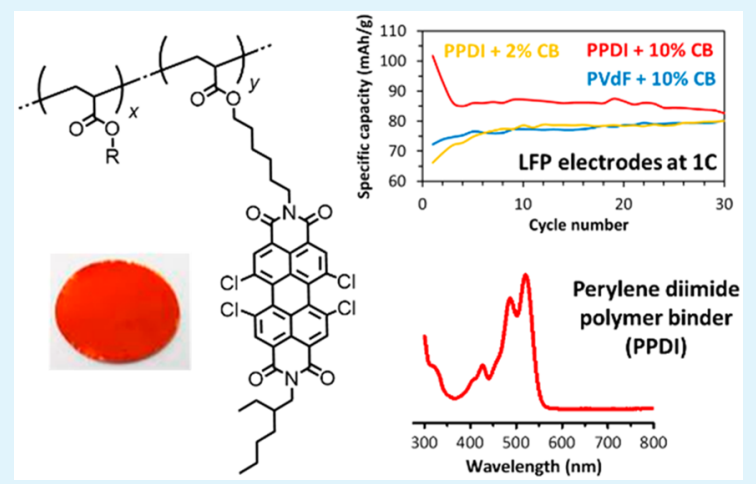

KEYWORDS: perylene dye, conductive polymer, battery binder, Li-ion batteries, redox active polymer

$\mathrm{W}$ ith nearly three decades of dominance in energy storage technologies, lithium-ion batteries (LIBs) continue to be mainstream power sources for many day-to-day applications such as portable electronics, power tools, drones, and electric vehicles. Due to their fast rechargeability and high capacity, Liion batteries have been an integral part of the development of the above applications. ${ }^{1}$ Recently, the construction of the Tesla giant power pack exemplifies the huge potential of LIBs for stationary energy storage. Since its first commercialization in 1991 by Sony Corp., LIB electrode formulation, materials, and its various components have been gradually evolved, which translates into incremental increases in energy density $(\sim 3 \times)$ and cost reduction, thus promptly responding to the demands of consumer electronics. ${ }^{1}$ However, Li-ion batteries now need an overhaul in order to adopt new functionalities such as photo-rechargeability $^{2}$ and mechanical flexibility ${ }^{3}$ or shape conformity as is highlighted by the emergence of wearable electronics and autonomously powered devices. To date, most of Li-ion battery research aimed at improving LIBs performance metrics is focused on battery active materials, electrolytes, carbon additives, separators, and battery packaging. ${ }^{4}$ But, there is another additive component typically used in battery electrode formulation that is key to achieving stable electrochemical performance: a polymeric binder. Although used in small amounts up to $5 \mathrm{wt} \%$ in Li-ion electrodes, ${ }^{5}$ polymeric binders are considered as dead volume because they are not intended to participate in electrochemical reactions that produce battery capacity but as structural promoters. The same holds true for carbon additives as they are mainly used to improve electronic conductivity across electrodes, but are incapable of maintaining electrical contact during structural changes of electrodes ${ }^{6}$ or electrode deformation upon battery bending. Therefore, development of an electrochemically active polymeric binder (as opposed to passive binders, such as poly(vinylidene fluoride) (PVdF)) and/or imparting additional functionalities to binders is critical to cope with the need to make Li-ion batteries more efficient in terms of energy density and to streamline the design of photorechargeable and flexible batteries.

Recently, studies have focused on conductive polymer binders, ${ }^{6}$ which can theoretically allow electrodes to gain up to $10-15 \%$ more active mass loading because a conductive additive such as carbon powder is no longer required to make active layers electronically conductive. An additional benefit is that by using only battery active materials and conductive binders, a more intimate electronic contact can be established between active particles if a good adhesion of the active layer to current collectors is achieved. Two types of conductive

Received: September 12, 2019

Accepted: February 19, 2020

Published: February 19, 2020 
binders have been developed so far, by relying on the polymer backbone ${ }^{7}$ for conductivity or along the side chain (mediated by $\pi-\pi$ stacking). ${ }^{8}$ These conductive polymers tend to significantly improve electrochemical and mechanical properties of electrodes when they are functionalized. ${ }^{9}$ For imparting multiple functions (e.g., electronic conductivity, surface compatibility, and binding ability), three main designs can be considered: first, tailoring the polymer molecular structure via polymer modification during synthesis; ${ }^{7}$ second, creating controlled nanostructures via in situ polymerization in the presence of functionalized dopants (e.g., 3D nanostructured polymer gels); ${ }^{10}$ third, making composites via hybridization of polymer with functional materials. ${ }^{11}$ Among these, tailoring polymer structures is very appealing because it allows for the design of highly functionalized polymers, which could be directly applied to different battery chemistries (only requiring the addition of an electroactive material). However, more versatile and scalable conductive polymer binders still need to be explored. For this, organic molecules/structures that can be easily tailored and that are furnished with advanced functionalities (such as a redox active group) are of particular interest.

Among conductive polymers, perylene diimide based polymers (PPDIs) are an interesting class of materials widely exploited in photovoltaics. ${ }^{12}$ However, since the synthesis of PPDI materials as processable compounds (with improved solubility) has been very challenging, they have only been used so far as redox active material in Li batteries. ${ }^{13}$ But in fact, an ideal polymer binder for battery application should have a low glass transition temperature $\left(T_{\mathrm{g}}\right)$ and adjustable adhesive properties and to be able to facilitate stacking of its polycyclic aromatic subunits for electronic conduction. Perylene-based main chain polymers are readily synthesized from perylene dianhydride (PDA) by direct imidization, but this produces highly insoluble, stiff, and unprocessable polymers (similar to the route in Scheme 1a, black arrows, direct imidization). ${ }^{14}$ Alternatively, polyacrylates bearing perylene diimides in the side chain have been synthesized by nitroxide mediated polymerizations starting from a perylene-functionalized acrylate, ${ }^{15}$ in which the synthesis and purification of highly reactive acrylates are cumbersome and inefficient. We therefore decided to prepare polyacrylates bearing PDIs in the side chain by a polymer analogous reaction as shown in the Scheme $1 \mathrm{~b}(4-6)$, i.e., the reaction of poly(acryloyl chloride) with a monohydroxy PDI (such as compound 4 in Scheme 1b). Using this approach, the degree of PDI functionalization can readily be tuned, attaching different PDIs is facile, and adhesive properties of the polymer are easily adjusted by a proper choice of alcohol-functionalized molecules that are attached to the polymer backbone in a successive step. The reason for this choice of the polyacrylate backbone is its low $T_{g}$, which should produce very flexible and easily processable polymer at ambient conditions. To this end, developing an efficient scalable synthesis route for such a monohydroxy PDI was the main challenge of this work.

At least three methods are known for the synthesis of nonbay substituted PDIs with different substituents at each imide position. ${ }^{16,17}$ However, monohydroxy tetrachloro-PDIs (such as compound $\mathbf{4}$ in Scheme $1 \mathrm{~b}$ ) have been previously synthesized by a one-step reaction in which two different amines react simultaneously with 1,6,7,12-tetrachloroperylene dianhydride (tetrachloro-PDA). ${ }^{18}$ This method yields a statistical mixture of two symmetric and one nonsymmetric
Scheme 1. (a) Schematic Representation of the New ScaleUp Synthesis Pathway Developed; (b) Synthesis of the Asymmetric Perylene Diimide Alcohols (1-4); (c) Synthesis of the Desired Analogous Polymers via Grafting (4-6)

a
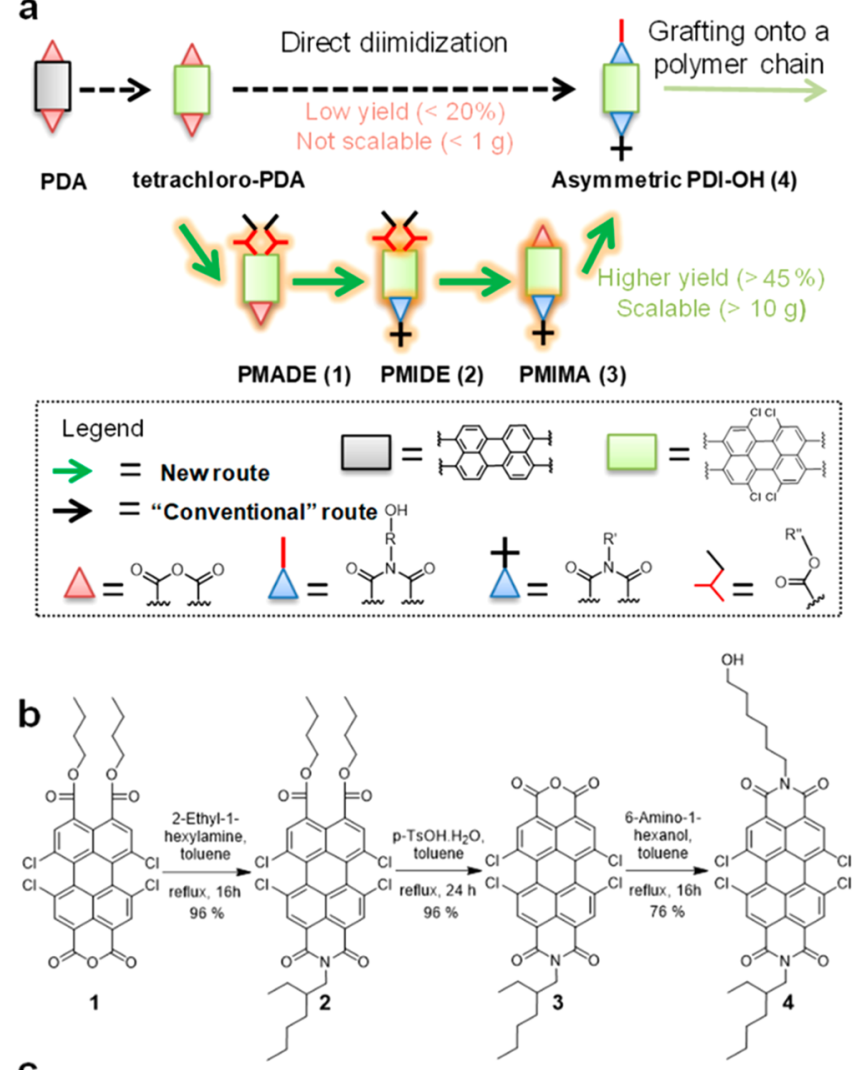

C

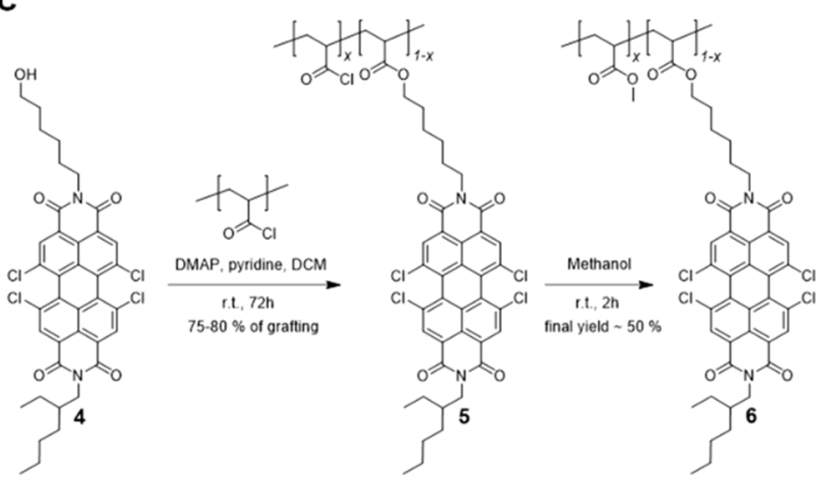

PDIs. This approach may be acceptable for a quick and smallscale exploratory synthesis using low-cost starting materials. At a multigram-scale, however, the separation of the three products is neither efficient nor easy to perform. To bypass these bottlenecks in PPDI's synthesis and to achieve an efficient, scalable and user-friendly synthesis of compound $\mathbf{4}$, we developed a new synthesis route, as shown in Scheme 1a, green arrows (see the Supporting Information (SI)), by exploiting the chemistry that was recently developed in our group for preparing nonsymmetrically peri substituted bayhalogenated perylene tetracarboxylic acid derivates. ${ }^{19,20}$

Subsequently to this step-by-step diimidization, $9 \mathrm{~g}$ of alcohol compound 4 was synthesized (with a final yield of $46 \%$ from PDA) and grafted readily on a poly(acryloyl chloride) $\left(\sim 10000 \mathrm{~g} \mathrm{~mol}^{-1}\right)$, followed by a treatment with dry methanol 
to react the remaining acryloyl functionalities, to obtain polymer 6 (as shown in Scheme 1). ${ }^{21,22}$ The degree of functionalization by reaction with compound 4 is $75-80 \%$, according to the ${ }^{1} \mathrm{H}$ NMR analysis, which implies that the theoretical molecular weight of the polymer molecules greatly increases, resulting in a number-average molecular weight $\left(M_{n}\right)$ of at least $60000 \mathrm{~g} \mathrm{~mol}^{-1}$ (see Supporting Information Figure S3). Clearly, this value is superior to what has been reported for materials obtained by the direct polymerization of PDIbearing acrylates ${ }^{15}$ and even the ones obtained by "click" chemistry. ${ }^{23}$ Liquid state ${ }^{1} \mathrm{H}$ NMR analysis was performed to determinate the purity and the degree of grafting of compound 4 on the poly(acryloyl chloride). The ${ }^{1} \mathrm{H}$ NMR spectrum of polymer $\mathbf{6}$ in chloroform is shown in Figure 1. In this spectrum

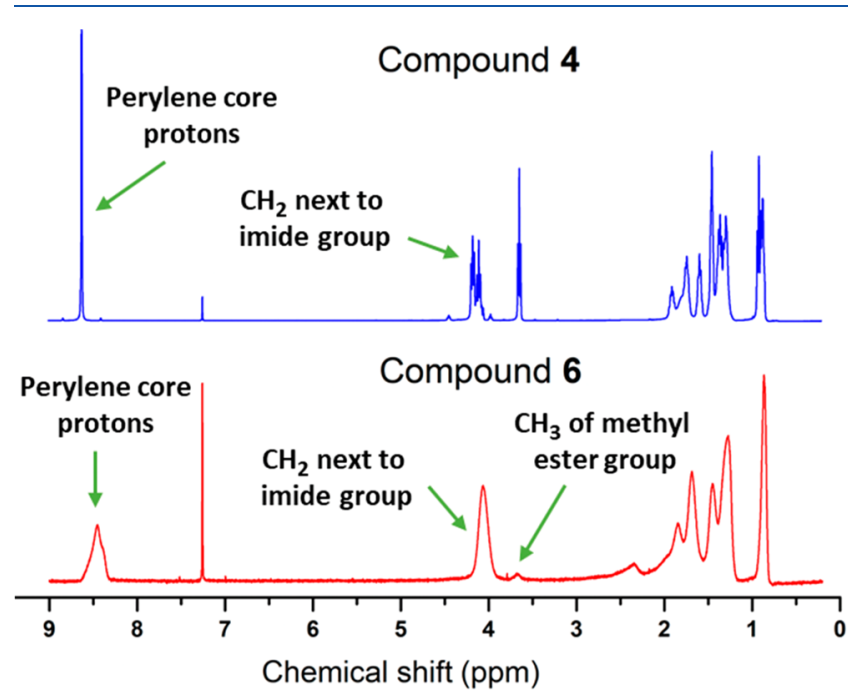

Figure 1. ${ }^{1} \mathrm{H}$ NMR spectra of compounds 4 and 6 (i.e., perylene diimide and PPDI).

the characteristic broad peaks of a polymer were observed. The degree of substitution is easily obtained by integrating the methyl ester and aromatic perylene protons. The NMR spectrum suggests that, in contrast to compound 4, in polymer 6 the ortho protons on the perylene core are inequivalent.

Optical characterization of polymer 6 in solution (Scheme 1c), by UV-vis (Figure 2a) and fluorescence spectroscopy, indicates a strong absorption from 370 to $550 \mathrm{~nm}$ and a strong reduction of the fluorescence quantum yield, $\Phi_{\mathrm{F}}$, by a factor 2.5. While compound 4 is a strongly fluorescent $\left(\Phi_{\mathrm{F}} \sim 0.83\right)$, as expected for this type of molecule, ${ }^{19}$ the fluorescence of polymer $\mathbf{6}$ is severely quenched by the close proximity of the PDI chromophores $\left(\Phi_{\mathrm{F}} \sim 0.35\right)$. In the solid state, however, polymer 6 is nonfluorescent. X-ray diffractions (Figure 2b), obtained with a $\mathrm{Cu} \mathrm{K} \alpha$ source, however, display a broad diffraction pattern, around $20-25^{\circ}$, indicating stacking of the aromatic planes with a large $4-4.5 \AA$ spacing, similar to the observations reported by Song et al. ${ }^{18}$ Since we observed this difference in stacking of our polymer before and after casting (Figure 2c,d), we carried out small-angle X-ray scattering/ wide-angle X-ray scattering (SAXS/WAXS) measurements to elucidate the possible morphological changes. For this purpose, analyses using synchrotron X-rays were performed on the PPDI powders before casting (i.e., unprocessed PPDI) and after solubilization of the polymer and evaporation of the solvent (i.e., processed PPDI). WAXS characterization (Figure 2e) reveals similar spectra of the two powders indicating
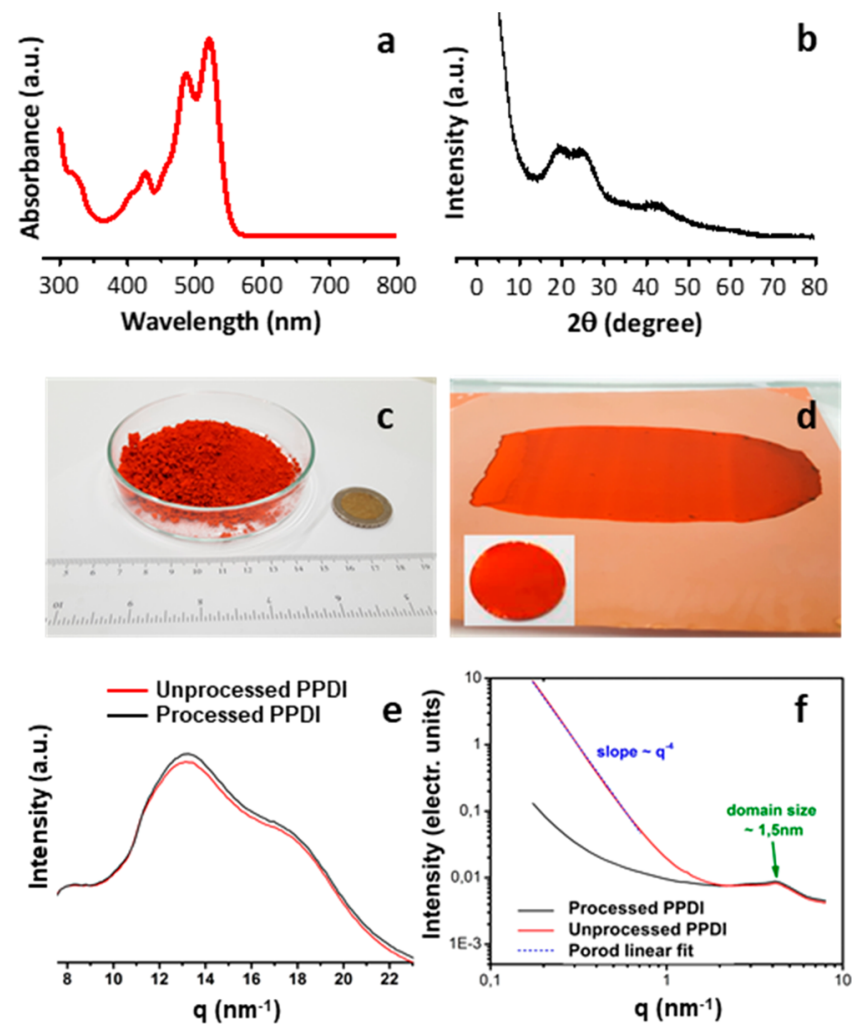

Figure 2. (a) UV-vis absorbance spectrum of the PPDI in chloroform. (b) X-ray diffraction patterns from as synthesized PPDI. (c) Unprocessed PPDI obtained as powder form. The yield from a single batch in small volumes shows its potential for scale-up. (d) PPDI coated on copper and aluminum current collector as electrodes (i.e., processed PPDI). (e) Wide-angle X-ray scattering (WAXS) spectra of unprocessed and processed PPDI powders. (f) Small-angle X-ray scattering (SAXS) spectra of unprocessed and processed PPDI powders with a Porod linear fit.

comparable long-range structure. Two broad peaks at 13.2 and $17.4 \mathrm{~nm}^{-1}$ are observed, corresponding to $d$-spacings of 4.76 and $3.6 \AA$, respectively. The latter is in line with typical values of $\pi-\pi$ stacking distances reported in the literature. ${ }^{24}$ However, the low intensity suggests that stacking occurs only on a comparatively small length scale. In this regard, SAXS provides more insights (Figure 2f). The peak at $4.2 \mathrm{~nm}^{-1}$ points to a microphase separation on a scale of $\sim 1.5 \mathrm{~nm}$. The strong decrease in scattering intensity in the low- $q$ range for the processed PPDI stems from the reduction in grain boundaries, which is due to polymer rearrangement. The slope and shape of the scattering curve further indicate that these grains are spherically shaped and are in the micrometer range. The presumable presence of such porosity after electrode processing is essential for quick electrolyte uptake, which may be favorable to ionic conductivity. In addition, thermogravimetric analysis (TGA) was performed on this polymer (see SI Figure S5), and this shows a high temperature of decomposition starting around $350{ }^{\circ} \mathrm{C}$, which is exceptional for a conductive polymer and close to the very good heat resistant PVdF (which has a decomposition temperature of $\left.400{ }^{\circ} \mathrm{C}\right) .{ }^{25}$

The next step was to evaluate the electrochemical performance of PPDI in Li half-cells using commercial lithium iron phosphate, $\mathrm{LiFePO}_{4}$ (LFP) as active material (as working electrode) and metallic $\mathrm{Li}$ (as counter electrode). We chose 

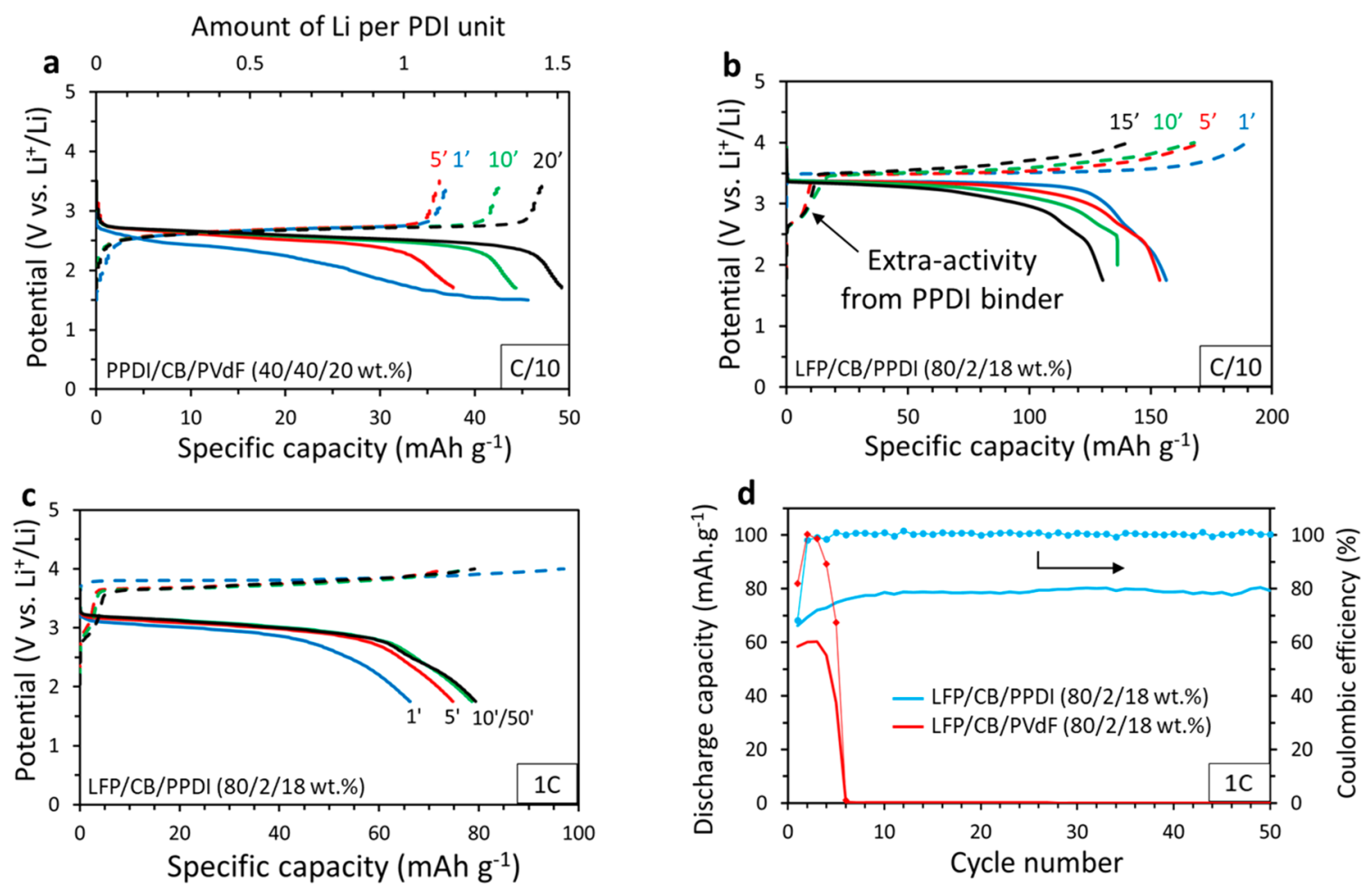

Figure 3. Charge/discharge curves of (a) PPDI/CB/PVdF (40/40/20 (wt \%)) with a first cycle at $\mathrm{C} / 20$ and sequential cycles at $\mathrm{C} / 10(1 \mathrm{C}=65$ $\left.\mathrm{mA} \mathrm{g}^{-1}\right)$, (b) LFP/CB/PPDI $\left(80 / 2 / 18\left(\right.\right.$ wt \%)) at C/10 (1C = $\left.170 \mathrm{~mA} \mathrm{~g}^{-1}\right)$, and (c) LFP/CB/PPDI $\left(80 / 2 / 18\left(\right.\right.$ wt \%)) at $\left.1 \mathrm{C} \mathrm{(170} \mathrm{mA} \mathrm{g}^{-1}\right) .(\mathrm{d})$ Cycling performance of LFP/CB/PPDI (80/2/18 (wt \%), in blue) and LFP/CB/PVdF (80/2/18 (wt \%), in red) at $1 \mathrm{C}\left(170 \mathrm{~mA} \mathrm{~g}{ }^{-1}\right)$. In panels $\mathrm{a}-\mathrm{c}$, dashed lines are charge curves and solid lines are discharge curves.

$\mathrm{LFP}^{26}$ because, alongside its commercial importance as one of the most stable cathode materials, electrodes containing conventional PVdF binders normally require up to or more than $10 \%$ carbon, ${ }^{27,28}$ especially if the active particles are bare (non-carbon coated) LFP, because LFP is an insulator. Therefore, electrochemical performance heavily depends on such a critical amount of carbon additive to provide the required level of electronic conductivity across LFP-based electrodes, and this therefore can serve as a benchmark for evaluating the role of PPDI in providing electronic conductivity in battery electrodes.

During electrode fabrication we noted that PPDI had a very low solubility in $N$-methyl-2-pyrrolidone (NMP), which is the commercial standard solvent used in Li-ion battery industries for making battery electrodes. It is worth mentioning that intensive research is underway to avoid $\mathrm{NMP}^{29}$ as battery solvent because of its toxicity in addition to its energy intensive evaporation and recovery lines. Instead, PPDI tends to dissolve freely in solvents such as chloroform, toluene, and chlorobenzene. This is based on the observation that when PPDI only (Figure 2c) is dissolved in these solvents, it produces high-quality coatings, as shown in Figure $2 \mathrm{~d}$. Using these solvents purely for electrode processing is still impractical since they evaporate too quickly, making it impossible to cast battery slurry onto the current collector. Therefore, a solvent mixture of chlorobenzene and NMP with a 1:1 volume ratio was used to dissolve PPDI for processing the slurry with LFP, resulting in homogeneous coatings that strongly bind to the current collector. Despite the fact that this mixture allows for processing the slurry and coating, identifying suitable single solvents for both PPDI dispersion and battery electrode ingredients is still necessary for commercial application.
However, here our main aim is to demonstrate the suitability of PPDI as an active binder in place of a passive binder (PVdF) (Figure $3 a-d)$. All electrodes were made via casting procedures under identical conditions (except PVdF electrodes that were cast using pure NMP solvent as this is the industrial standard), and no additional electrode optimization procedures were performed such as calendaring. Here the ideal is to replace both PVdF and carbon additive completely as PPDI can in principle act as both the binder and electronic conductor. But practically, while the electroactive PPDI polymers can readily replace the passive PVdF binder, PPDI electronic conductivity is limited due to electron diffusion through only $\pi-\pi$ stacked perylene domains.

We therefore added carbon black (CB) but only as low as $2 \%$, to improve electron pathways (percolation) among PPDI conductive domains, LFP and aluminum current collector. Therefore, the final electrode composition was altered to 80:2:18 (wt \%). We chose a high amount of binder (18 wt \%) to ensure a pronounced difference between PPDI and PVdF. Therefore, the aim of this study is not to optimize LFP battery performance but to demonstrate that a fluorine-free and multifunctional binder based on PPDI is achievable (for processing Li-ion cathodes). At this carbon weight percent, the sheet resistance measurements show electrodes containing PPDI/LFP exhibit lower resistance (av $\sim 313 \Omega / \square$ ) than the electrodes containing PVdF/LFP $(\sim 640 \Omega / \square)$; see Supporting Information for more details.

Since PPDI is electroactive, the evaluation of its practical capacity was performed by blending $40 \mathrm{wt} \%$ PPDI with $40 \mathrm{wt}$ $\% \mathrm{CB}$ and $20 \mathrm{wt} \% \mathrm{PVdF}$. This ratio was chosen for assessing the full electrochemical activities of PPDI as an active material. PPDI has a theoretical capacity of $\sim 65 \mathrm{mAh} \mathrm{g}^{-1}$ (via exchange 
of two Li ions), but the practical capacity, as shown in Figure $3 \mathrm{a}$, is $\sim 50 \mathrm{mAh} \mathrm{g}^{-1}$, with a prominent voltage plateau (redox potential) around $2.6 \mathrm{~V}$ vs $\mathrm{Li}^{+} / \mathrm{Li}$. Also, $\mathrm{CV}$ data of PPDI only (Figure S9 in the Supporting Information) on Al foil confirms PPDI's redox activity and an electrochemical stability up to 3.9 $\mathrm{V}$ vs $\mathrm{Li}^{+} / \mathrm{Li}$. Therefore, the electrochemical activity of PPDI binder, in tandem with LFP, can improve battery capacity as confirmed by the small first plateaus at $2.6 \mathrm{~V}$ during charging in Figure $3 b, c$, which is not typical for electrodes processed with PVdF.

At $\mathrm{C} / 10$ cycling (where $\mathrm{C} / 10$ means that the full charge of the battery is reached in $10 \mathrm{~h}$ ), electrodes composed of $80 \mathrm{wt}$ $\%$ LFP, 2 wt \% CB, and 18 wt \% PPDI (Figure 3b) have average voltage plateaus of $3.35 \mathrm{~V}$ (discharge) and $3.51 \mathrm{~V}$ (charge) $\mathrm{vs}^{\mathrm{Li}^{+}} / \mathrm{Li}$ in the first cycle. At $1 \mathrm{C}$ (Figure 3c), an increase in polarization by $\sim 0.21 \mathrm{~V}$ can be seen but PPDI electrodes displayed surprisingly a much higher cycling stability at this rate. To explain this phenomenon, we hypothesize that at faster rates less PPDI are lithiated, which lessens structural changes of the polymer matrix, thus making PPDI as a more efficient conductive binder. At this same composition, electrodes using the inert PVdF as binder exhibited very poor electrochemical performance (high polarization, $>0.65 \mathrm{~V}$ ) and their capacities faded significantly just after a few cycles, as shown Figure 3d (more information and galvanostatic cycling tests can be found in Figure S7).

PVdF electrodes with an optimal ratio of $\mathrm{CB}$, i.e., $10 \mathrm{wt} \%$, were also made for comparing performances (Supporting Information). To sum up, PPDI electrodes deliver better capacity and cyclability compared to electrodes with PVdF. The electrochemical trends observed on electrodes with PPDI are similar to what has been reported on carbon coated LFP electrodes (containing an optimal amount of carbon additives). ${ }^{30}$ Remarkably, cycle life performance at a $1 \mathrm{C}$ rate in Figure 3d shows almost no capacity fade (except for the first and second cycles) and the capacity is also similar to that of the PVdF-based electrode at higher carbon content (see SI Figure S6). Their Coulombic efficiencies (discharge/charge capacity ratio) were nearly $100 \%$ at this rate, which is indicative of electrochemical reversibility of the charge/ discharge cycles of electrodes with PPDI.

Our study shows that battery electrodes processed with PPDI binder can considerably minimize the use of carbon additive and can replace PVDF, both of which are considered to be the dead volume of electrodes. This also means if suitable single solvents able to disperse both PPDI and battery ingredients to an optimal degree were identified, PPDI electroactive binder could virtually eliminate the need of carbon additive. The implication is that over $98 \%$ of the battery electrode mass can be of electrochemically active particles/phase, leading to improved energy density. We therefore remark that adhesive properties of active layers when PPDI is used as binder calls for further investigation to determine suitable substrate pretreatments and solvents to process slurries into electrodes with a strongly adhesive active layer on current collectors as well as additional electrode optimization. Nevertheless, these good electrochemical results obtained with very low amounts of conductive additives (as small as $2 \%$ carbon) establish that Li-ion battery electrodes can benefit from PPDI dyes' multiple roles, as they can serve as active binder, electroactive material, and light harvester.

In conclusion, we have presented a new and scalable approach to synthesize processable perylene diimide (PPDI) polymers. We demonstrated a facile way of grafting a hydroxylfunctionalized PDI and an aliphatic alcohol onto a polyacrylate chain, which can be used to systematically adjust the relevant properties of polymer binders such as adhesion, flexibility, and electrolyte compatibility. This opens up the possibility of using PDIs with different substitution patterns to tune the conductivity and redox potential of polymer binders in a systematic manner. Compared with the conventional PVdF electrodes (with 10\% CB and 10\% PVdF and with $2 \% \mathrm{CB}$ and $18 \%$ PVdF), PPDI electrodes (with 2\% CB and 18\% PPDI) offer improved capacities due to PPDI's electrochemical activity, which effectively minimizes the use of carbon additive and eliminates the passive binder (PVdF). Further optimization of PPDI can be performed, notably by finding the best compromise between binding ability and conductivity via the adjustment of the degree of monohydroxy PDI grafted and by improving the electronic conductivity via the stacking of PDI side chains. If an optimized conductivity performance can be reached, it is possible to consider the elimination of all additional conductive additives, thus gaining up to $10-15 \%$ more mass loading of active particles/phase in Li-ion electrode formulation, leading to improved energy densities. Considering PPDIs light absorption in the visible spectrum (ca. $550 \mathrm{~nm}$ ), PPDI-functionalized dyes as Li-ion electrode binder point to new opportunities for developing energy storage technologies with in-built photofunctionality.

\section{ASSOCIATED CONTENT}

\section{Supporting Information}

The Supporting Information is available free of charge at https://pubs.acs.org/doi/10.1021/acsaem.9b01225.

Syntheses of the study's compounds; nuclear magnetic resonance characterization of polymers; additional electrochemical data including cycling performances, cyclic voltammetry results, and sheet resistance measurements (PDF)

\section{AUTHOR INFORMATION}

\section{Corresponding Authors}

Chandramohan George - Department of Radiation Science and Technology/Reactor Institute Delft, Delft University of Technology, 2629 JB Delft, The Netherlands; Dyson School of Design Engineering, Imperial College London, SW7 2AZ London, United Kingdom; (1) orcid.org/0000-0003-29066399; Email: chandramohan.george@imperial.ac.uk

Wolter F. Jager - Faculty of Applied Sciences, Department of Chemical Engineering (OMI-ChemE), Delft University of Technology, 2629 HZ Delft, The Netherlands; (1) orcid.org/ 0000-0001-7664-6949; Email: W.F.Jager@tudelft.nl

Erik M. Kelder - Department of Radiation Science and Technology/Reactor Institute Delft, Delft University of Technology, 2629 JB Delft, The Netherlands; ALISTORE-ERI European Research Institute, 80000 Amiens, France; Email: E.M.Kelder@tudelft.nl

\section{Authors}

Pierre Ranque - Faculty of Applied Sciences, Department of Chemical Engineering (OMI-ChemE), Delft University of Technology, 2629 HZ Delft, The Netherlands; Institut des Sciences Analytiques et de Physicochimie pour l'Environnement et les Materiaux, IPREM, E2S-UPPA/CNRS/Universite Pau \& Pays Adour, 64000 Pau, France; ALISTORE-ERI European 
Research Institute, 80000 Amiens, France; 이이이.org/00000003-3222-0983

Rajeev K. Dubey - Faculty of Applied Sciences, Department of Chemical Engineering (OMI-ChemE), Delft University of Technology, 2629 HZ Delft, The Netherlands; O orcid.org/ 0000-0001-5165-7801

Remco van der Jagt - Department of Radiation Science and Technology/Reactor Institute Delft, Delft University of Technology, 2629 JB Delft, The Netherlands; 이이.org/ 0000-0003-4239-7758

Delphine Flahaut - Institut des Sciences Analytiques et de Physicochimie pour l'Environnement et les Materiaux, IPREM, E2S-UPPA/CNRS/Université Pau \& Pays Adour, 64000 Pau, France; ALISTORE-ERI European Research Institute, 80000 Amiens, France; O orcid.org/0000-0001-6787-2928

Rémi Dedryvère - Institut des Sciences Analytiques et de Physicochimie pour l'Environnement et les Materiaux, IPREM, E2S-UPPA/CNRS/Universite Pau \& Pays Adour, 64000 Pau, France; ALISTORE-ERI European Research Institute, 80000 Amiens, France; 이이. orcid.org/0000-0001-5125-640X

Marcus Fehse - Department of Radiation Science and Technology/Reactor Institute Delft, Delft University of Technology, 2629 JB Delft, The Netherlands; Dutch-Belgian (DUBBLE), ESRF-The European Synchrotron, 38043 Cedex 9 Grenoble, France; ALISTORE-ERI European Research Institute, 80000 Amiens, France; 이이.org/0000-0001-8650-6974

Panagiotis Kassanos - The Hamlyn Centre, Imperial College London, SW7 2AZ London, United Kingdom; (1) orcid.org/ 0000-0003-4597-8558

Ernst J. R. Sudhölter - Faculty of Applied Sciences, Department of Chemical Engineering (OMI-ChemE), Delft University of Technology, 2629 HZ Delft, The Netherlands; 이이.org/ 0000-0003-3296-953X

Complete contact information is available at: https://pubs.acs.org/10.1021/acsaem.9b01225

\section{Notes}

The authors declare no competing financial interest.

\section{ACKNOWLEDGMENTS}

This work was carried out in the framework of AlistoreEuropean Research Institute. P.R. is grateful to CNRS for financial support. C.G. acknowledges funding from Marie Skłodowska-Curie Action H2020-MSCA-IF (under Grant Agreement No.704659 FlexBatteries). R.v.d.J. is grateful to The Netherlands Organization for Scientific Research (NWO) under the OTP Grant No. 15785.

\section{ABBREVIATIONS}

$\mathrm{CB}$, carbon black

DCM, dichloromethane

DMAP, (4-dimethylamino)pyridine

LFP, lithium iron phosphate

PDA, perylene-3,4,9,10-tetracarboxylic dianhydride

PDI, perylene diimide

PDI-OH (4), monohydroxy tetrachloroperylene diimide

PMADE (1), 1,6,7,12-tetachloroperylene-3,4,9,10-tetracarboxy monoanhydride dibutyl ester

PMIDE (2), tetrachloroperylene monoimide dibutyl ester PMIMA (3), tetrachloroperylene monoanhydride monoimide

PPDI, polymer of perylene diimide
PVdF, poly(vinylidene difluoride)

$p$-TsOH, $p$-toluenesulfonic acid

\section{REFERENCES}

(1) Gür, T. M. Review of electrical energy storage technologies, materials and systems: Challenges and prospects for large-scale grid storage. Energy Environ. Sci. 2018, 11 (10), 2696-2767.

(2) Ahmad, S.; George, C.; Beesley, D. J.; Baumberg, J. J.; De Volder, M. Photo-Rechargeable Organo-Halide Perovskite Batteries. Nano Lett. 2018, 18, 1856-1862.

(3) Ahmad, S.; Copic, D.; George, C.; De Volder, M. Hierarchical Assemblies of Carbon Nanotubes for Ultraflexible Li-Ion Batteries. Adv. Mater. 2016, 28, 6705-6710.

(4) Li, M.; Lu, J.; Chen, Z.; Amine, K. 30 Years of Lithium-Ion Batteries. Adv. Mater. 2018, 30, 1800561.

(5) Bresser, D.; Buchholz, D.; Moretti, A.; Varzi, A.; Passerini, S. Alternative binders for sustainable electrochemical energy storage the transition to aqueous electrode processing and bio-derived polymers. Energy Environ. Sci. 2018, 11, 3096-3127.

(6) Kwon, T.-W.; Choi, J. W.; Coskun, A. The emerging era of supramolecular polymeric binders in silicon anodes. Chem. Soc. Rev. 2018, 47, 2145-2164.

(7) Wu, M.; Xiao, X.; Vukmirovic, N.; Xun, S.; Das, P. K.; Song, X.; Olalde-Velasco, P.; Wang, D.; Weber, A. Z.; Wang, L.-W.; Battaglia, V. S.; Yang, W.; Liu, G. Toward an Ideal Polymer Binder Design for High-Capacity Battery Anodes. J. Am. Chem. Soc. 2013, 135, 1204812056.

(8) Park, S.-J.; Zhao, H.; Ai, G.; Wang, C.; Song, X.; Yuca, N.; Battaglia, V. S.; Yang, W.; Liu, G. Side-Chain Conducting and PhaseSeparated Polymeric Binders for High-Performance Silicon Anodes in Lithium-Ion Batteries. J. Am. Chem. Soc. 2015, 137, 2565-2571.

(9) Shi, Y.; Zhou, X.; Yu, G. Material and Structural Design of Novel Binder Systems for High-Energy, High-Power Lithium-Ion Batteries. Acc. Chem. Res. 2017, 50, 2642-2652.

(10) Shi, Y.; Zhou, X.; Zhang, J.; Bruck, A. M.; Bond, A. C.; Marschilok, A. C.; Takeuchi, K. J.; Takeuchi, E. S.; Yu, G. Nanostructured Conductive Polymer Gels as a General Framework Material To Improve Electrochemical Performance of Cathode Materials in Li-Ion Batteries. Nano Lett. 2017, 17, 1906-1914.

(11) Zhong, H.; He, A.; Lu, J.; Sun, M.; He, J.; Zhang, L. Carboxymethyl Chitosan/Conducting Polymer as Water-Soluble Composite Binder for $\mathrm{LiFePO} 4$ Cathode in Lithium Ion Batteries. J. Power Sources 2016, 336, 107-114.

(12) A., V.; Liu, S.-W.; Wong, K.-T. Organic polymeric and small molecular electron acceptors for organic solar cells. Mater. Sci. Eng., $R$ 2018, 124, 1-57.

(13) Iordache, A.; Delhorbe, V.; Bardet, M.; Dubois, L.; Gutel, T.; Picard, L. Perylene-Based All-Organic Redox Battery with Excellent Cycling Stability. ACS Appl. Mater. Interfaces 2016, 8, 22762-22757.

(14) Wang, Z. Y.; Qi, Y.; Gao, J. P.; Sacripante, G. G.; Sundararajan, P. R. Duff, J. D. Synthesis, Characterization, and Xerographic Electrical Characteristics of Perylene-Containing Polyimides. Macromolecules 1998, 31, 2075-2079.

(15) Lindner, S. M.; Thelakkat, M. Nanostructures of n-Type Organic Semiconductor in a p-Type Matrix via Self-Assembly of Block Copolymers. Macromolecules 2004, 37, 8832-8835.

(16) Robb, M. J.; Newton, B.; Fors, B. P.; Hawker, C. J. One-Step Synthesis of Unsymmetrical N-Alkyl-N'-aryl Perylene Diimides. J. Org. Chem. 2014, 79, 6360-6365.

(17) Huang, C.; Barlow, S.; Marder, S. R. Perylene-3,4,9,10tetracarboxylic Acid Diimides: Synthesis, Physical Properties, and Use in Organic Electronics. J. Org. Chem. 2011, 76, 2386-2407.

(18) Song, W.; Wu, J.; Yang, G.; Han, H.; Xie, M.; Liao, X. Precisely designed perylene bisimide-substituted polyethylene with a high glass transition temperature and an ordered architecture. RSC Adv. 2015, 5, 68765-68722.

(19) Dubey, R. K.; Westerveld, N.; Sudhölter, E. J. R.; Grozema, F. C.; Jager, W. F. Novel derivatives of 1,6,7,12-tetrachloroperylene- 
3,4,9,10-tetracarboxylic acid: synthesis, electrochemical and optical properties. Org. Chem. Front. 2016, 3, 1481-1492.

(20) Dubey, R. K.; Westerveld, N.; Grozema, F. C.; Sudhölter, E. J. R.; Jager, W. F. Facile Synthesis of Pure 1,6,7,12-Tetrachloroperylene3,4,9,10-tetracarboxy Bisanhydride and Bisimide. Org. Lett. 2015, 17, $1882-1885$.

(21) Kouwer, P. H. J.; Mijs, W. J.; Jager, W. F.; Picken, S. J. Synthesis and Characterization of a Novel Liquid Crystalline Polymer Showing a Nematic Columnar to Nematic Discotic Phase Transition. Macromolecules 2000, 33, 4336-4342.

(22) Lapinski, A.; Graja, A.; Olejniczak, I.; Bogucki, A.; Polomska, M.; Baffreau, J.; Perrin, L.; Leroy-Lhez, S.; Hudhomme, P. Vibrational and electronic properties of perylenediimide linked to fullerene and tetrathiafulvalene. Mol. Cryst. Liq. Cryst. 2006, 447, 405-421.

(23) Lang, A. S.; Muth, M.-A.; Heinrich, C. D.; Carassco-Orozco, M.; Thelakkat, M. Pendant perylene polymers with high electron mobility. J. Polym. Sci., Part B: Polym. Phys. 2013, 51, 1480-1486.

(24) Janiak, C. A critical account on $\pi-\pi$ stacking in metal complexes with aromatic nitrogen-containing ligands. J. Chem. Soc., Dalton Trans. 2000, 0, 3885-3896.

(25) Cao, J.-H.; Zhu, B.-K.; Ji, G.-L.; Xu, Y.-Y. Preparation and characterization of PVDF-HFP microporous flat membranes by supercritical CO2 induced phase separation. J. Membr. Sci. 2005, 266, $102-109$.

(26) Lu, J.; Chen, Z.; Ma, Z.; Pan, F.; Curtiss, L. A.; Amine, K. The role of nanotechnology in the development of battery materials for electric vehicles. Nat. Nanotechnol. 2016, 11, 1031-1038.

(27) Zaghib, K.; Shim, J.; Guerfi, A.; Charest, P.; Striebel, K. A. Effect of Carbon Source as Additives in $\mathrm{LiFePO}_{4}$ as Positive Electrode for Lithium-Ion Batteries. Electrochem. Solid-State Lett. 2005, 8, A207-A210.

(28) Wang, J.; Sun, X. Olivine $\mathrm{LiFePO}_{4}$ : the remaining challenges for future energy storage. Energy Environ. Sci. 2015, 8, 1110-1138.

(29) Wood, D. L., III; Li, J.; Daniel, C. Prospects for reducing the processing cost of lithium ion batteries. J. Power Sources 2015, 275, 234-242.

(30) Paolella, A.; Bertoni, G.; Marras, S.; Dilena, E.; Colombo, M.; Prato, M.; Riedinger, A.; Povia, M.; Ansaldo, A.; Zaghib, K.; Manna, L.; George, C. Etched Colloidal $\mathrm{LiFePO}_{4}$ Nanoplatelets toward HighRate Capable Li-Ion Battery Electrodes. Nano Lett. 2014, 14, 68286835. 